\title{
Características do Exercício do Controle e a Composição dos Conselhos de Administração no Novo Mercado
}

\section{Characteristics of Control Exercise and the Composition of the Boards of Directors in Novo Mercado}

\author{
Filipe Manarte Scaramussa \\ Universidade Federal do Espírito Santo \\ filipemanarte@hotmail.com \\ Patricia Maria Bortolon \\ Universidade Federal do Espírito Santo \\ patricia.bortolon@ufes.br
}

\begin{abstract}
Resumo
O presente estudo, de caráter descritivo, analisa como as características de controle, observadas a partir da participação no capital votante e da informação declarada à CVM, se relacionam com as composições dos conselhos de administração das 142 empresas listadas no Novo Mercado. A expectativa com a criação do Novo Mercado era que as exigências deste segmento favoreceriam menor concentração de controle e conselhos de administração mais independentes. A partir dos dados de participação acionária no capital votante e declaração de acionista controlador nas bases da CVM, foi possível constatar o exercício do controle sem necessariamente haver a detenção da maioria do capital votante. As empresas foram então separadas em diferentes categorias, observando-se a existência de acionista apontado como controlador e se ele detinha, de fato, mais de $50 \%$ do capital votante; e de acordo de acionistas que estabelecesse o controle. Os dados apontam uma forte presença de conselheiros, inclusive independentes, eleitos por acionistas controladores; e que 6 empresas estão descumprindo o regulamento do Novo Mercado quanto a exigência mínima de conselheiros independentes. Em relação as características dos conselhos de administração e do controle, os resultados dos testes indicam ausência de diferenças estatisticamente significativas entre empresas com acionistas controladores absolutos (com mais de 50\% dos votos) e empresas com controladores autodeclarados, que não possuem maioria absoluta do capital votante. Isto levanta questionamento se considerar como corte para estabelecimento do controle a posse de mais de $50 \%$ dos votos, utilizado na maioria das pesquisas nacionais, seria a prática mais recomendável.
\end{abstract}

Palavras-chave: acionista controlador, conselheiro independente, conselho de administração, estrutura de propriedade, Novo Mercado.

\begin{abstract}
This descriptive study analyzes how the control characteristics, observed from the participation in the voting capital and the information declared to the CVM, relate to the composition of the boards of directors of the 142 companies listed on Novo Mercado. The expectation with the creation of Novo Mercado was that the requirements of this segment would favor lower concentration of control and more independent boards of directors. From the data on shareholding in the voting capital and declaration of controlling shareholder in the CVM bases, it was possible to verify the exercise of control without necessarily having most of the voting capital. The companies were then separated into different categories, noting the existence of a shareholder appointed as controlling shareholder and whether he held more than $50 \%$ of the voting capital; and of a shareholders' agreement that established control. The data indicate a strong presence of directors, including independent, elected by controlling shareholders; and
\end{abstract}


that 6 companies are not complying with the Novo Mercado regulation regarding the minimum requirement of independent directors. Regarding the characteristics of the board and of control, the tests results indicate the absence of statistically significant differences between companies with absolute controlling shareholders (with more than $50 \%$ of the votes) and companies with self-declared controlling shareholders, which don't hold an absolute majority of the voting capital. This raises the question whether considering more than $50 \%$ of the votes as a control cut-off, as used in most national polls, would be the most recommended practice.

Keywords: board of directors, controlling shareholder, independent director, Novo Mercado, ownership structure.

\section{Introdução}

O mercado de capitais brasileiro tem como tradição uma estrutura de propriedade altamente concentrada (VALADARES; LEAL, 2000; CARVALHAL DA SILVA; LEAL, 2003; CHAVEZ; SILVA, 2009). Entretanto o estudo de Gorga (2009) aponta que, apesar das firmas do mercado tradicional terem mantido seu padrão concentrado de estrutura acionária, o nível de concentração de propriedade sofreu uma diminuição relevante com o ingresso de múltiplas empresas no Novo Mercado.

O conselho de administração é um órgão central para a governança corporativa (IBGC, 2015) e tem seus membros escolhidos pelos acionistas em assembleias gerais ordinárias. Portanto é possível que as configurações dos conselhos de administração tenham sofrido mudanças a partir desta redução na concentração de propriedade das empresas do Novo Mercado.

Os dados coletados indicam que o Novo Mercado reúne companhias com diferentes tipos de estrutura de controle, tais como controle estabelecido de forma individual, controle coletivo estabelecido via acordo de acionistas e ainda empresas com estrutura dispersa, sem controle definido. Estas firmas possuem diferenças no principal problema de agência de acordo com o tipo de estrutura que apresentam, de forma que a configuração necessária para o bom funcionamento do conselho de administração seja distinta em cada caso. Os conselheiros independentes, por sua vez, ocupam um papel de destaque na tentativa de mitigar os conflitos de agência inevitavelmente presentes nas empresas (GELMAN, 2012).

A estrutura de propriedade e controle (LEAL; SILVA; VALADARES, 2002; PROCIANOY; SCHNORRENBERGER, 2004; ALDRIGHI; MAZZER NETO, 2007; CAIXE; KRAUTER, 2013; DE ANDRADE; BRESSAN; IQUIAPAZA, 2014) e o conselho de administração (DUTRA; SAITO, 2002; ANDRADE et al, 2009; GELMAN, 2012; BRUGNI et al, 2013; BRUGNI, 2016) são assuntos amplamente pesquisados devido a sua reconhecida importância para a governança corporativa. $\mathrm{O}$ presente estudo buscou explorar ambos no contexto do segmento de maior qualidade de governança da B3, com um enfoque diferenciado na questão do controle.

Trabalhos realizados no Brasil tendem a considerar a posse de mais de 50\% do capital votante como corte para definir o controle (LEAL; SILVA; VALADARES, 2002; CARVALHAL, 2012; BORTOLON, 2013; ALDRIGHI; POSTALI; DIAZ, 2018), visto que a maioria das empresas nacionais apresentam estrutura acionária concentrada. Todavia alguns países possuem o mercado com predominância da estrutura de propriedade dispersa, caso de EUA e Reino Unido, com alguns pesquisadores considerando que percentuais inferiores podem ser suficientes para garantir o controle, como 20\% (LA PORTA; LOPEZ-DE-SILANES; SHLEIFER, 1999) ou até mesmo 10\% (CLAESSENS; DJANKOV; LANG, 2000).

Este trabalho buscou verificar se existem evidências de uma mudança no panorama brasileiro quanto ao percentual de votos que de fato garante ao acionista o controle das firmas 
listadas no Novo Mercado, ou seja, se na prática os acionistas conseguem exercer o controle das empresas com um percentual de votos inferior à maioria absoluta (50\% mais um). Para isso, observou-se a relação entre estrutura de propriedade, inclusive os efeitos dos acordos de acionistas vigentes, e a configuração do conselho de administração. De forma geral, os acionistas baseiam sua política de indicação de conselheiros considerando seus próprios interesses e a manutenção do seu poder (ANDERSON; REEB, 2004; DAHYA; DIMITROV; MCCONNELL, 2008; FONTES FILHO; PICOLIN, 2008), espera-se que a quantidade e o tipo de conselheiros indicados pelos acionistas seja uma boa medida de sua capacidade de exercer o controle da empresa.

Ante o exposto, o presente estudo propõe a seguinte pergunta de pesquisa: como as características de controle se relacionam com as composições dos conselhos de administração das empresas listadas no Novo Mercado, em especial quanto a presença de conselheiros independentes e sua indicação por parte do bloco controlador?

Esta pesquisa, de caráter descritivo, tem como objetivos específicos: (I) contribuir para um melhor entendimento sobre a atual conjuntura da estrutura de propriedade e das configurações dos conselhos de administração no Novo Mercado; (II) identificar se, no Novo Mercado, o corte de maioria absoluta dos votos (50\% mais 1) é de fato um pré-requisito para o estabelecimento do controle; e (III) verificar se o regulamento do Novo Mercado está sendo seguido quanto a exigência mínima de conselheiros independentes.

Com isso, espera-se contribuir de forma prática indicando ao regulador e ao mercado quais firmas estão descumprindo o regulamento do Novo Mercado com relação ao mínimo exigido de conselheiros independentes. Busca-se contribuir para a literatura analisando se a maioria absoluta dos votos é o único fator a ser considerado para estabelecer o controle das empresas; e fornecendo uma visão condensada da estrutura de propriedade e configuração dos conselhos de administração das empresas analisadas.

Os resultados obtidos apontam uma forte presença de conselheiros, inclusive independentes, eleitos pelo bloco controlador, o que levanta questionamentos quanto em que medida os conselhos de administração conseguem atuar de forma autônoma e imparcial. Foram identificadas 6 empresas descumprindo o regulamento do Novo Mercado quanto a exigência mínima de conselheiros independentes. Por fim, com relação as variáveis analisadas, não foram encontradas diferenças entre o acionista controlador com maioria absoluta dos votos e o acionista que se declara controlador, via formulário de referência, mesmo sem possuir mais de $50 \%$ das ações ordinárias. Este achado pode impactar pesquisas futuras que venham a observar a estrutura de controle.

\section{Referencial teórico}

\subsection{Estrutura de propriedade}

Conforme Jensen e Meckling (1976), um relacionamento de agência consiste em um contrato no qual o principal transmite ao agente a autoridade para a tomada de decisões, permitindo-o desempenhar um serviço em favor do principal. Considerando que as ações de ambas as partes visam a satisfação máxima de seus interesses pessoais, há razão para crer que o agente não agirá no melhor interesse do principal em todas as ocasiões. O principal então incorreria em custos de agência para promover o alinhamento entre os interesses do agente e os seus.

Os protagonistas de maior relevância nos conflitos de agência presentes nas empresas se alteram conforme o tipo de estrutura de propriedade e controle na qual elas estão inseridas. Em mercados caracterizados por propriedade acionária dispersa, caso de Reino Unido e EUA, os acionistas são detentores de pequenas parcelas do capital e dos votos das companhias, possuindo menor capacidade de fiscalização dos diretores responsáveis pela administração do 
negócio quando comparados aos acionistas controladores existentes em mercados com alta concentração acionária. Assim, os principais conflitos de agência nesse cenário ocorrem devido a interesses opostos entre acionistas e executivos (SHLEIFER; VISHNY, 1997).

Entretanto a maioria dos países, como é o caso do Brasil, apresentam uma estrutura acionária concentrada, na qual o acionista controlador é quem de fato exerce o poder de gestão da empresa, devido à forte influência que possui sobre os executivos, e tem a capacidade de expropriar os demais proprietários. Daí surgem os problemas de agência entre acionistas controladores e acionistas minoritários, que são preponderantes em mercados com alto grau de concentração do controle (ALDRIGHI; MAZZER NETO, 2005).

La Porta et al. (1999) analisaram as estruturas de propriedade de grandes empresas em 27 países diferentes, observando uma ampla concentração do controle em quase todos eles. Os autores apontam para uma forte relação inversa entre nível de proteção legal aos investidores e o grau de concentração acionária em determinado mercado. Dessa forma, espera-se que países como o Brasil, que oferecem pouca proteção aos direitos dos investidores, apresentem uma maior concentração de votos nas mãos de um número reduzido de grandes acionistas. Isso se dá pela necessidade de possuir participações amplas o suficiente que permitam ao proprietário exercer um melhor monitoramento dos gerentes da empresa, reduzindo os problemas resultantes dos conflitos de interesse entre principal e agente.

Pode-se argumentar que a presença de acionistas detentores de elevadas parcelas do capital levaria a um aumento no valor de mercado das firmas, ao sinalizar para potenciais investidores externos a existência de uma dedicação e compromisso maior por parte do principal proprietário, já que possui valores significativos aplicados no negócio. Acionistas detentores de grandes blocos de ações tendem a diminuir os custos de agência dispendidos no alinhamento entre os interesses dos diretores e os dos sócios, apresentando uma maior capacidade de monitoramento das ações da administração.

Entretanto a presença de grandes acionistas favorece a ocorrência de expropriação dos minoritários por parte do controlador, o que pode se dar de diversas formas, tais como: a nomeação dele mesmo ou de parentes para cargos privilegiados dentro da empresa; a avaliação de investimentos e projetos da empresa utilizando critérios baseados em interesses pessoais; o pagamento de salários excessivos a si próprio ou a seus familiares; a transferência de recursos entre empresas do mesmo grupo a preços muito abaixo dos praticados pelo mercado; a utilização dos ativos da empresa como garantia para transações pessoais; a prática de insider trading (OKIMURA; SILVEIRA; ROCHA, 2007).

O mercado de capitais brasileiro segue uma tradição de propriedade concentrada, com investimentos médios por parte dos acionistas controladores muito acima do mínimo necessário para manutenção do controle das companhias ((LEAL; SILVA; VALADARES, 2002). O trabalho elaborado por Carvalhal da Silva e Leal (2003) analisou uma amostra composta por 225 companhias, com base em informações do ano 2000, e constatou que $90 \%$ delas tinha um único acionista com mais de $50 \%$ do capital votante. Nas demais empresas da amostra sem um acionista majoritário com mais de $50 \%$ dos votos, os autores detectaram que o maior acionista detinha, em média, 37\% do capital votante.

Com o Novo mercado sendo criado apenas em 2000, estudos anteriores ainda não apresentavam em seus resultados as possíveis mudanças que seriam promovidas com a criação dos segmentos especiais de listagem. Gorga (2009) realizou um trabalho analisando informações com base no ano de 2007, ou seja, já considerando os anos de boom de IPOs na BM\&FBovespa e as consequências da criação dos segmentos especiais de listagem. Dentre as sociedades da amostra, foram detectadas 183 companhias do segmento tradicional e 92 companhias do Novo Mercado. O estudo aponta que não houve mudança no padrão de propriedade concentrada com relação às empresas do mercado tradicional, apresentando em seus resultados aproximadamente $72,67 \%$ das companhias tendo um acionista controlador com 
mais de $50 \%$ do capital votante e o maior acionista detendo, em média, 65,50\% das ações com direito a voto.

Já a parte da amostra contendo especificamente empresas listadas no Novo Mercado identificou, pela primeira vez no Brasil, um cenário com mais firmas sem um único acionista controlador. Das 92 entidades consideradas, apenas 27 (menos de 30\%) tinham um acionista com mais de $50 \%$ dos votos, nesse caso detendo em média $60,85 \%$ do capital votante. Nas restantes 65 companhias, a média de votos do maior acionista era 26,23\%, sendo que a média do capital votante do maior acionista para a amostra de empresas do Novo Mercado foi de $36,39 \%$.

Entretanto há um fator importante a ser considerado no estudo e que não havia sido abrangido pelos resultados anteriormente citados: os acordos de acionistas. Gorga (2009) passou a considerar que os acordos de acionistas cujas partes fossem individualmente não controladoras, detendo menos de 50\% do capital votante, mas que através dos dispositivos do acordo passassem a estabelecer o controle da empresa, ao deter mais de 50\% dos votos, devem ser levados em conta nos resultados da pesquisa.

Assim, considerando os 20 acordos de controle presentes na amostra do estudo para empresas do Novo Mercado, o quadro de concentração sofreu uma mudança significativa. Das 92 companhias, o total delas apresentando controle definido (seja por acionista controlador individual com mais de 50\% do capital votante, seja por acordo de acionistas que estabelecesse o controle) passou para 47, de forma que apenas 45 permaneciam sem controlador. A autora então conclui dizendo que, apesar do avanço ocorrido com casos de dispersão acionária, ao examinar os dados com mais cuidado percebeu que, ao contrário do que se esperava, não teria ocorrido mudança significativa no perfil de propriedade acionária no Brasil.

\subsection{Controle das empresas}

Não existe um consenso estabelecido na literatura acadêmica apontando um percentual específico de votos que garanta o controle de uma empresa. O limite mínimo tomado como determinante para o controle varia de caso a caso, de acordo com a organização acionária, a existência de contratos entre os proprietários que vinculem os votos e a estrutura de votos nas assembleias ordinárias de cada companhia.

Em países como EUA e Reino Unido, que apresentam um alto grau de dispersão da propriedade acionária, há quem defenda que acionistas detentores de $20 \%$ do capital votante já podem ser efetivamente considerados controladores (LA PORTA; LOPEZ-DE-SILANES; SHLEIFER, 1999). Alguns autores ainda afirmam que, dependendo do quão pulverizada for a estrutura de propriedade analisada, até mesmo $10 \%$ dos votos já pode garantir o controle da empresa ao sócio (CLAESSENS; DJANKOV; LANG, 2000).

Todavia a maioria dos países apresenta elevada concentração acionária, de forma que acionistas individuais necessitam possuir um percentual superior a 50\% dos votos para garantir o domínio da tomada de decisão na firma. Dessa forma, sua posição predominante nas assembleias não estaria suscetível a variações na estrutura de propriedade, tampouco a criação de blocos envolvendo pequenos acionistas via dispositivos contratuais, assumindo assim o controle absoluto da empresa. Por esse motivo, trabalhos realizados no Brasil, como Leal, Silva e Valadares (2002), Carvalhal (2012), Bortolon (2013) e Aldrighi, Postali e Diaz (2018), tendem a considerar como corte para um acionista individual assumir o controle da empresa a posse de $50 \%$ do capital votante.

Existe ainda a possibilidade de se assumir o controle via acordo de acionistas, tratandose de um contrato formal voluntário assinado entre dois ou mais acionistas, com a possibilidade de estabelecer diretrizes sobre como seus signatários deverão votar nas assembleias e eleger membros do conselho de administração. Nesse caso, é possível que vários acionistas detentores de parcelas menores do capital votante se unam e alcancem o controle integral da firma, sem 
precisar arcar com o ônus financeiro proveniente da posse de um número maior de ações (GORGA, 2009).

As empresas brasileiras são obrigadas a indicar para a CVM, no formulário de referência, de forma nominal, quem são os acionistas que detém pelo menos 5\% do capital da companhia, quais as suas participações no capital e se são acionistas controladores ou não. Analisando-se os dados coletados para realização do presente estudo, observou-se em algumas empresas a presença de um acionista individual ou um grupo de signatários de determinado acordo de acionistas, que apesar de não possuir mais de 50\% do capital votante, era apontado como controlador. Uma possível explicação para esse fenômeno seria que, apesar de não possuir maioria absoluta se observado o total de votos, esse proprietário detém o domínio pleno dentro do quórum de uma assembleia específica, sendo então considerado controlador naquele dado momento.

Existem ainda empresas com capital disperso - caso não muito comum de ser encontrado no contexto brasileiro - que não se enquadram em nenhuma das situações descritas anteriormente. Esse tipo de sociedade apresenta uma estrutura de propriedade composta por múltiplos acionistas detentores de pequenas parcelas do capital votante, sem a presença de um proprietário predominante ou de um contrato entre sócios forte o suficiente para assumir o controle das decisões nas assembleias da firma.

\subsection{Conselho de administração}

O conselho de administração é um órgão central para a governança corporativa e sua principal função evoluiu com o passar do tempo. Inicialmente assumiu um papel voltado ao aconselhamento, com presença predominante de conselheiros internos, como os principais administradores da firma, e alguns conselheiros externos com conexões profundas com a empresa. Mais recentemente, a atividade primária dos conselhos passou a ser de monitoramento, com tendência a serem compostos majoritariamente por conselheiros independentes (GORDON, 2010).

O conselho de administração possui presença obrigatória em todas as empresas brasileiras de capital aberto, conforme determina a Lei 6.404/76. É o órgão encarregado do processo decisório em relação ao direcionamento estratégico da organização, sendo visto como o elo no relacionamento entre sócios e gestores (IBGC, 2015). Seus membros são eleitos pelos acionistas, possuindo a capacidade de decidir em nome dos proprietários. Dentre suas funções cabe destacar o monitoramento da gestão, contratando, demitindo e sugerindo a remuneração dos executivos, a supervisão da prestação de contas e de quaisquer outros atos relacionados à administração da empresa, visando garantir que os diretores irão utilizar os poderes a eles atribuídos em prol dos interesses dos proprietários (VILLALONGA et al., 2018).

Devido ao importante papel exercido pelo conselho de administração, diversas pesquisas têm como objeto de estudo a composição desse órgão, tais como Dutra e Saito (2002), Anderson e Reeb (2004), Brugni et al. (2013), Alves, Couto e Francisco (2015) e Brugni et al. (2018). Os conselheiros podem ser categorizados em internos, quando são também empregados da organização ou fazem parte da alta gestão; externos, caso não tenham vínculo atual comercial ou empregatício com a empresa, mas possuam alguma relação com ela ou com partes a ela relacionadas que afetem sua independência; e independentes.

Uma consequência importante da presença de um conselho efetivo e competente é a diminuição de conflitos de interesse entre proprietários e gestores. Contudo, sendo uma das atividades fundamentais do órgão fiscalizar a administração como um todo, o fato de diretores da alta gestão estarem autorizados a serem eleitos conselheiros pode afetar a sua efetividade. Isso é especialmente preocupante em casos em que o presidente da diretoria ou seu principal executivo ocupa também o cargo de presidente do conselho (ANDRADE et al., 2009). 
Tendo em vista que o mercado de crédito brasileiro ainda é consideravelmente precário se comparado ao de países economicamente mais desenvolvidos (DE OLIVEIRA; WOLF, 2016), as empresas cada vez mais se utilizam do mercado de ações para angariar novos recursos a serem utilizados para financiar seu crescimento. Entretanto, há de se considerar a lógica de que os investidores optarão por aplicar seu patrimônio em projetos nos quais se sintam mais seguros e que apresentem menores chances de serem expropriados. A partir daí cresce a importância da figura do conselheiro independente e de maiores graus de independência dentro dos conselhos de administração, como forma de sinalização ao mercado de melhores práticas de governança corporativa e um ambiente de maior segurança, visando atrair novos investidores.

O amplo estudo realizado por Gordon (2010) sobre o histórico da evolução do papel do conselheiro independente nos Estados Unidos entre 1950 e 2005 demonstra o crescimento da presença e importância desse tipo de conselheiro dentro dos conselhos de administração das companhias. Apesar de ser um estudo restrito àquele país, seus dados são relevantes para a compreensão do papel assumido pelo conselheiro independente como um mecanismo central de Governança Corporativa.

O estudo indica que os conselheiros internos representavam cerca de 50\% dos membros do conselho de administração em 1950, tendo esse número sido reduzido para aproximadamente $15 \%$ em 2005. Em contrapartida, a figura do conselheiro independente, que representava em torno de $20 \%$ em 1950, passou a representar $75 \%$ dos membros dos conselhos das companhias americanas em 2005. A explicação para essa mudança, segundo o próprio autor, reside na evolução do papel do conselheiro de administração, que inicialmente atuava como um consultor e passou a atuar principalmente no monitoramento das práticas da diretoria.

O Novo Mercado foi o primeiro segmento especial de listagem criado pela BM\&FBovespa em 2000, não havendo na época, no entanto, previsão dos Conselheiros Independentes. Os segmentos especiais de listagem foram objeto de atualização em 2006 e em 2011 e foi a partir daí que surgiu a figura dos conselheiros independentes no Brasil, trinta anos depois da criação da Lei das SAs (Lei 6.404/1976), em 2006.

O Novo Mercado é atualmente o segmento de listagem de maior nível e exigência com relação às boas práticas de Governança Corporativa e seu regulamento atual, que entrou em vigor em 02 de janeiro de 2018, trata sobre os conselheiros independentes no Conselho de Administração nos Artigos 15, 16 e 17. A exigência é que o conselho deve ser composto por, no mínimo, 2 (dois) conselheiros independentes - ou $20 \%$ (vinte por cento), o que for maior. O regulamento ainda define a independência, afirmando que deve ser considerada a relação do conselheiro com a companhia, com o acionista controlador direto ou indireto, com seus administradores e com as sociedades controladas e coligadas. Exige ainda a não vinculação do voto do conselheiro por parte de acordo de acionistas, ausência de vínculo empregatício com a companhia ou o acionista controlador nos últimos três anos, entre outros requisitos (B3, 2017). Diante desse cenário, percebe-se que segmentos de listagem e conselheiros independentes são conceitos que caminham lado a lado na conjuntura brasileira de governança corporativa.

Segundo Clarke (2007), proteger os direitos dos acionistas minoritários, monitorar transações com partes relacionadas e servir como um consultor são as três principais funções de um conselheiro independente. Ele acredita que mesmo um único conselheiro independente isolado é capaz de apresentar certo grau de proteção aos acionistas minoritários ao possuir acesso a determinadas informações e decisões sobre a companhia, podendo dar conhecimento aos proprietários em eventuais abusos praticados pelo grupo controlador ou pela diretoria, diminuindo o problema de agência. Isso é corroborado por Neves et al. (2017) ao afirmarem que os conselheiros independentes possuem importância fundamental no sistema de Governança Corporativa por serem peça-chave para a redução do problema de agência. 
Considerando-se que o mercado de capitais brasileiro apresenta característica de propriedade concentrada e grandes benefícios privados do controle, é razoável concluir que o papel do conselheiro independente é de mitigar o problema de representação entre acionistas majoritários e minoritários, bem como reduzir os benefícios da posse do controle (GELMAN, 2012). Portanto os conselheiros independentes assumem função fundamental nas empresas que possuem controle definido. Entretanto, não se pode ignorar a sua importância nas empresas de capital disperso, que não apresentam acionista controlador com mais de $50 \%$ do capital votante ou acordo de acionistas definindo o controle, uma vez que essas organizações apresentam diretorias com papel predominante e também necessitam dos benefícios apresentados pelos conselheiros independentes na proteção dos proprietários (IBGC, 2015).

Existe, no entanto, algo que pode levantar dúvidas quanto a real independência de membros do conselho. $\mathrm{O}$ fato de não haver qualquer restrição presente no regulamento do Novo Mercado quanto à possibilidade de conselheiros independentes serem eleitos por acionistas controladores chama a atenção para uma possível perda de independência. Afinal a maioria das empresas brasileiras de capital aberto ainda apresenta um alto grau de concentração do controle, com a presença de grandes acionistas com força suficiente para fiscalizar os atos da gestão e com a possibilidade de extrair benefícios privados do controle via expropriação dos acionistas minoritários. Nesse caso é razoável levantar o questionamento se o conselheiro é de fato independente, ainda que tenha sido eleito por uma figura preponderante dentro da firma como o acionista controlador.

\section{Metodologia}

Dado que o mercado de capitais brasileiro tem como tradição uma estrutura de propriedade altamente concentrada, estudos nacionais consideram como corte para estabelecimento do controle das empresas a posse de mais de $50 \%$ dos votos (LEAL; SILVA; VALADARES, 2002; CARVALHAL, 2012; BORTOLON, 2013; ALDRIGHI; POSTALI; DIAZ, 2018). Entretanto alguns trabalhos identificaram uma diminuição na concentração de propriedade das empresas listadas no Novo Mercado, o que não ocorreu no segmento tradicional (GORGA, 2009; STERNBERG; LEAL; BORTOLON, 2011; LEAL; CARVALHAL; IERVOLINO, 2015). Considerando-se que um dos objetivos deste trabalho é identificar se o corte de maioria absoluta dos votos é de fato um pré-requisito para o estabelecimento do controle, ou se houve uma mudança neste padrão devido a uma redução na concentração de propriedade, a pesquisa foi delimitada somente às empresas do Novo Mercado.

O presente estudo analisou informações de todas as empresas listadas no Novo Mercado, totalizando 142 companhias observadas. Os dados referentes à estrutura dos conselhos de administração e às propriedades acionárias foram coletados da base de dados ComDinheiro® em 04 de novembro 2018, representando as informações contidas no formulário de referência mais recente quanto a essa data. A tabela 1 traz uma relação das variáveis analisadas.

As variáveis 1 a 6 foram utilizadas para analisar a estrutura dos conselhos de administração, tendo sido observadas as características para tamanho do conselho; número de conselheiros internos, externos e independentes; quantidade de conselheiros independentes eleitos pelo controlador e total de conselheiros eleitos pelo controlador. Essas variáveis foram utilizadas em estudos anteriores, como Dutra e Saito (2002) e Brugni et al (2018). Cabe destacar que foram levados em conta somente os conselheiros efetivos, desconsiderando-se da análise todos os conselheiros suplentes.

Com relação à estrutura de controle das companhias, representada pelas variáveis 7 a 11, identificou-se a participação percentual do maior acionista, analisando-se então todos os acordos de acionistas em vigor naquele momento. Os acordos de acionistas foram observados através dos formulários de referência divulgados pelas empresas em 2018 ou nos documentos de acordos de acionistas disponibilizados nos dados cadastrais da empresa na CVM ou ainda 
no próprio endereço eletrônico da companhia, esse somente quando necessário por falta de informação nas duas primeiras opções.

Tabela 1: Descrição das variáveis analisadas

\begin{tabular}{|c|c|c|c|}
\hline $\mathbf{N}^{\mathbf{o}}$ & Variável & Tipo de variável & Descrição \\
\hline \multicolumn{4}{|r|}{ Variáveis observadas } \\
\hline 1 & qtca & quantitativa & Quantidade de conselheiros no CA \\
\hline 2 & qintca & quantitativa & Quantidade de conselheiros internos no CA \\
\hline 3 & qextca & quantitativa & Quantidade de conselheiros externos no CA \\
\hline 4 & qindca & quantitativa & Quantidade de conselheiros independentes no CA \\
\hline 5 & qtec & quantitativa & $\begin{array}{l}\begin{array}{l}\text { Quantidade de conselheiros do CA eleitos pelo acionista ou bloco } \\
\text { controlador }\end{array}\end{array}$ \\
\hline 6 & qindec & quantitativa & $\begin{array}{l}\text { Quantidade de conselheiros independentes do CA eleitos pelo acionista ou } \\
\text { bloco controlador }\end{array}$ \\
\hline 7 & pam & quantitativa & Participação percentual de ações do acionista majoritário \\
\hline 8 & pac & quantitativa & $\begin{array}{c}\text { Participação percentual de ações dos signatários de acordo de acionistas } \\
\text { apontados como controladores }\end{array}$ \\
\hline 9 & ctrl & dummy & $\begin{array}{l}\text { Indica a existência de acionista individual ou bloco de acionistas apontado } \\
\text { pela empresa como controlador }\end{array}$ \\
\hline 10 & ctrlabs & dummy & $\begin{array}{l}\text { Indica a presença de acionista individual ou bloco de acionistas que soma } \\
\text { mais de } 50 \% \text { do capital votante }\end{array}$ \\
\hline 11 & aactrl & dummy & $\begin{array}{l}\text { Indica se a empresa possui acordo de acionistas em vigor que estabelece o } \\
\text { controle }\end{array}$ \\
\hline \multicolumn{4}{|r|}{ Variáveis calculadas } \\
\hline 12 & pint & quantitativa & Percentual de conselheiros internos no CA \\
\hline 13 & pext & quantitativa & Percentual de conselheiros externos no CA \\
\hline 14 & pind & quantitativa & Percentual de conselheiros independentes no CA \\
\hline 15 & pec & quantitativa & $\begin{array}{l}\text { Percentual de conselheiros do CA eleitos pelo acionista ou bloco } \\
\text { controlador }\end{array}$ \\
\hline 16 & pindec & quantitativa & $\begin{array}{l}\text { Percentual de conselheiros independentes do CA eleitos pelo acionista ou } \\
\text { bloco controlador }\end{array}$ \\
\hline
\end{tabular}

Fonte: Elaborada pelos autores.

Das 142 empresas da população, foram detectados e analisados acordos de acionistas em 66 delas. Destas, 42 informaram para a CVM o estabelecimento de controle através do acordo de acionistas; 16 apresentam acionista majoritário com mais de 50\% dos votos e ainda assim possuem acordo de acionistas em vigor; e 8 informam a não existência de acionista controlador apesar da presença desses dispositivos contratuais. 
Considerando-se que o regulamento do Novo Mercado não autoriza a emissão de ações sem direito a voto, as empresas da população foram classificadas em diferentes categorias quanto à estrutura de controle, conforme o quadro a seguir:

Tabela 2: Categorização da estrutura de propriedade

\begin{tabular}{|c|c|c|c|}
\hline Categoria & $\begin{array}{l}\text { Quantidade de } \\
\text { empresas }\end{array}$ & Nome da Categoria & Descrição \\
\hline 1 & 50 & $\begin{array}{l}\text { Controlador individual com mais } \\
\text { de } 50 \% \text { dos votos }\end{array}$ & $\begin{array}{l}\text { Todas as empresas nas quais o maior } \\
\text { acionista possui mais de } 50 \% \text { do } \\
\text { capital votante }\end{array}$ \\
\hline 1.1 & 5 & $\begin{array}{c}\text { Controlador individual com mais } \\
\text { de } 50 \% \text { dos votos via estrutura } \\
\text { indireta }\end{array}$ & $\begin{array}{l}\text { Todas as empresas nas quais o maior } \\
\text { acionista possui mais de } 50 \% \text { do } \\
\text { capital votante quando considerada a } \\
\text { estrutura indireta }\end{array}$ \\
\hline 2 & 28 & $\begin{array}{l}\text { Controle via acordo de acionistas } \\
\text { somando mais de } 50 \% \text { dos votos }\end{array}$ & $\begin{array}{c}\text { Empresas sem um acionista } \\
\text { individual controlando mais de } 50 \% \\
\text { do capital, porém com acordo de } \\
\text { acionistas cujos signatários somam } \\
\text { mais de } 50 \% \text { dos votos }\end{array}$ \\
\hline 3.1 & 8 & $\begin{array}{l}\text { Controle individual com menos } \\
\text { de } 50 \% \text { dos votos }\end{array}$ & $\begin{array}{l}\text { O maior acionista individual detém } \\
\text { menos de } 50 \% \text { do capital votante, } \\
\text { mas foi indicado pela empresa para a } \\
\text { CVM como sendo controlador }\end{array}$ \\
\hline 3.2 & 14 & $\begin{array}{l}\text { Controle via acordo de acionistas } \\
\text { somando menos de } 50 \% \text { dos } \\
\text { votos }\end{array}$ & $\begin{array}{c}\text { Acordo de acionistas cujos } \\
\text { signatários somam menos de } 50 \% \text { dos } \\
\text { votos, porém foram indicados pela } \\
\text { empresa para a CVM como sendo } \\
\text { controladores }\end{array}$ \\
\hline 3.3 & 37 & Sem controle definido & $\begin{array}{l}\text { Não foi identificado qualquer tipo de } \\
\text { controle }\end{array}$ \\
\hline
\end{tabular}

Fonte: Elaborada pelos autores.

Com relação ao controle das empresas, o presente estudo inicialmente considerou o mesmo parâmetro utilizado por Gorga (2009) e Carvalhal (2012), no qual são considerados como controladores apenas acionistas individuais ou blocos de membros de acordo de acionistas que detenham mais de $50 \%$ do capital votante das firmas. Entretanto as categorias 3.1 e 3.2 chamam a atenção uma vez que o acionista individual ou o grupo de acionistas que é apontado como controlador pelas próprias empresas em declaração para a CVM não detém mais de $50 \%$ do capital votante, ou seja, não possui maioria absoluta se observado o total de votos. Uma possível explicação para esses casos seria que o proprietário ou o bloco de signatários do acordo de acionistas em questão detém o domínio pleno dentro do quórum de uma assembleia específica, sendo então apontado controlador naquele momento.

Assim, os acionistas controladores das empresas que se enquadram nas categorias $1,1.1$ e 2 podem ser considerados controladores absolutos, uma vez que só deixam de ter o controle por iniciativa própria, tendo a sua disposição todos os meios necessários para mantê-lo. Entretanto para as categorias 3.1 e 3.2, como o acionista ou o conjunto de acionistas apontado como controlador não retém mais de $50 \%$ dos votos, é possível que o controle mude de mãos independentemente da vontade de quem o detém naquele momento, através da compra de ações por parte de outro sócio ou a criação de um novo bloco dominante via acordo de acionistas que some mais de $50 \%$ do capital votante. 
Esse trabalho se caracteriza como uma pesquisa descritiva, uma vez que foram coletados dados que permitem analisar, através de métodos estatísticos, como as características de controle se relacionam com as composições dos conselhos de administração da população de empresas listadas no Novo Mercado em novembro de 2018.

A apresentação dos dados coletados foi realizada com a utilização de estatística descritiva. Em seguida, buscando-se analisar os resultados encontrados para as diferentes categorias de controle identificadas, utilizou-se de testes paramétricos, na figura da análise de variância e de testes $t$ de diferença entre médias; e testes não paramétricos, representados por Kruskal-Wallis e Wilcoxon-Mann-Whitney.

\section{Resultados}

\subsection{Estatística descritiva}

A Tabela 3 apresenta a estatística descritiva das variáveis identificadas na Tabela 1 para as 142 empresas do Novo Mercado, devidamente classificadas entre as diferentes categorias de estrutura de controle apresentadas anteriormente.

O tamanho médio efetivo do conselho de administração para a população de empresas do Novo Mercado de 7,07 é semelhante aos valores encontrados por Brugni et al. (2018), que analisaram dados do período entre 2009 e 2013 e encontraram um tamanho médio próximo de 7 nos anos observados. Na tabela 3 é possível verificar que as empresas que indicaram a presença de um grupo controlador via acordo de acionistas, no caso representadas pelas categorias 2 e 3.2, apresentam um número de conselheiros maior do que as demais companhias, em termos de média e mediana.

Outra variável que chama a atenção é o percentual de conselheiros internos. Nas companhias sem controle definido o principal problema de agência tende a ser entre acionistas e administradores, uma vez que a diretoria em geral apresenta uma posição predominante devido à inexistência de um acionista controlador para melhor fiscalizar seus atos. Assim, nestes casos a fiscalização da diretoria está principalmente sob responsabilidade do conselho de administração, sendo indesejável que este apresente um número elevado de conselheiros internos por ameaçar comprometer sua independência e imparcialidade. Portanto espera-se que os acionistas das empresas com capital disperso busquem eleger mais conselheiros externos e independentes para defender os seus interesses, e consequentemente que os conselhos destas empresas apresentem um menor número de conselheiros internos.

Entretanto, a tabela 3 demonstra que a categoria com menor média percentual de conselheiros internos não foi a 3.3, representante das firmas sem controle definido, mesmo com apenas 14 das 37 empresas desta categoria possuindo conselheiros internos. Além disso, a empresa EVEN CONSTRUTORA E INCORPORADORA S/A, que detém o maior percentual de conselheiros internos dentro da população do Novo Mercado, apresenta capital disperso. Uma possível explicação para este fenômeno seria que os diretores destas firmas estão em uma situação dominante ao ponto de conseguir influenciar a indicação dos membros do conselho (BYRD; HICKMAN, 1992), aumentando o número de conselheiros internos eleitos e potencialmente reduzindo a capacidade do conselho de monitorar os atos da alta administração (CORBETTA; SALVATO, 2004). 
Tabela 3: Estatística Descritiva

\begin{tabular}{|c|c|c|c|c|c|c|}
\hline Dados & & $\begin{array}{l}\text { Tamanho } \\
\text { efetivo do }\end{array}$ & $\begin{array}{c}\text { Quantidade. } \\
\text { de } \\
\text { conselheiros }\end{array}$ & $\begin{array}{c}\% \text { de } \\
\text { conselheiros }\end{array}$ & $\begin{array}{c}\text { Quantidade } \\
\text { de } \\
\text { conselheiros }\end{array}$ & $\begin{array}{c}\% \text { de } \\
\text { conselheiros }\end{array}$ \\
\hline & Média & 6,84 & 0,62 & $9,72 \%$ & 3,70 & $53,34 \%$ \\
\hline Categoria 1 (50 & Mediana & 7,00 & 0,50 & $4,55 \%$ & 4,00 & $57,14 \%$ \\
\hline $\begin{array}{l}\text { empresas): } \\
\text { controlador }\end{array}$ & $\begin{array}{l}\text { Desv. } \\
\text { Pad }\end{array}$ & 1,63 & 0,70 & $10,99 \%$ & 1,54 & $16,88 \%$ \\
\hline individual com mais & Mínimo & 3,00 & 0,00 & $0,00 \%$ & 1,00 & $16,67 \%$ \\
\hline & Máximo & 11,00 & 2,00 & $33,33 \%$ & 7,00 & $85,71 \%$ \\
\hline Categoria 1.1 (5 & Média & 5,60 & 1,00 & $18,88 \%$ & 2,60 & $46,74 \%$ \\
\hline empresas): & Mediana & 5,00 & 1,00 & $20,00 \%$ & 3,00 & $40,00 \%$ \\
\hline $\begin{array}{c}\text { controlador } \\
\text { individual com mais }\end{array}$ & $\begin{array}{l}\text { Desv. } \\
\text { Pad. }\end{array}$ & 1,95 & 0,71 & $13,24 \%$ & 1,14 & $18,92 \%$ \\
\hline de $50 \%$ dos votos & Mínimo & 3,00 & 0,00 & $0,00 \%$ & 1,00 & $33,33 \%$ \\
\hline $\begin{array}{l}\text { via estrutura } \\
\text { indireta }\end{array}$ & Máximo & 8,00 & 2,00 & $33,33 \%$ & 4,00 & $80,00 \%$ \\
\hline & Média & 7,61 & 0,50 & $7,59 \%$ & 4,36 & $55,03 \%$ \\
\hline Categoria 2 (28 & Mediana & 7,50 & 0,00 & $0,00 \%$ & 4,00 & $58,57 \%$ \\
\hline $\begin{array}{l}\text { empresas): controle } \\
\text { via acordo de }\end{array}$ & $\begin{array}{l}\text { Desv. } \\
\text { Pad. }\end{array}$ & 1,99 & 0,64 & $10,36 \%$ & 2,04 & $20,70 \%$ \\
\hline $\begin{array}{l}\text { acionistas com mais } \\
\text { de } 50 \% \text { dos votos }\end{array}$ & Mínimo & 3,00 & 0,00 & $0,00 \%$ & 0,00 & $0,00 \%$ \\
\hline & Máximo & 11,00 & 2,00 & $33,33 \%$ & 8,00 & $83,33 \%$ \\
\hline Categoria 3.1 (8 & Média & 6,50 & 0,75 & $12,95 \%$ & 3,25 & $49,68 \%$ \\
\hline empresas): & Mediana & 6,50 & 1,00 & $12,50 \%$ & 3,50 & $46,53 \%$ \\
\hline $\begin{array}{c}\text { controlador } \\
\text { individual com }\end{array}$ & $\begin{array}{l}\text { Desv. } \\
\text { Pad. }\end{array}$ & 1,93 & 0,71 & $12,97 \%$ & 1,49 & $19,03 \%$ \\
\hline menos de $50 \%$ dos & Mínimo & 3,00 & 0,00 & $0,00 \%$ & 1,00 & $28,57 \%$ \\
\hline votos & Máximo & 9,00 & 2,00 & $33,33 \%$ & 5,00 & $80,00 \%$ \\
\hline Categoria 3.2 (14 & Média & 8,07 & 0,71 & $10,50 \%$ & 4,71 & $54,72 \%$ \\
\hline empresas): controle & Mediana & 7,50 & 1,00 & $8,33 \%$ & 3,50 & $56,35 \%$ \\
\hline $\begin{array}{c}\text { via acordo de } \\
\text { acionistas com }\end{array}$ & $\begin{array}{c}\text { Desv. } \\
\text { Pad. }\end{array}$ & 3,27 & 0,83 & $11,88 \%$ & 2,97 & $16,38 \%$ \\
\hline menos de $50 \%$ dos & Mínimo & 4,00 & 0,00 & $0,00 \%$ & 2,00 & $25,00 \%$ \\
\hline & Máximo & 15,00 & 3,00 & $37,50 \%$ & 10,00 & $83,33 \%$ \\
\hline & Média & 6,92 & 0,46 & $8,04 \%$ & 2,38 & $33,12 \%$ \\
\hline Categoria 3.3 (37 & Mediana & 7,00 & 0,00 & $0,00 \%$ & 2,00 & $27,27 \%$ \\
\hline $\begin{array}{c}\text { empresas): } \\
\text { empresas sem }\end{array}$ & $\begin{array}{l}\text { Desv. } \\
\text { Pad. }\end{array}$ & 2,02 & 0,65 & $12,28 \%$ & 2,15 & $27,92 \%$ \\
\hline controle definido & Mínimo & 3,00 & 0,00 & $0,00 \%$ & 0,00 & $0,00 \%$ \\
\hline & Máximo & 13,00 & 2,00 & $40,00 \%$ & 7,00 & $85,71 \%$ \\
\hline & Média & 7,07 & 0,58 & $9,44 \%$ & 3,52 & $48,10 \%$ \\
\hline População de & Mediana & 7,00 & 0,00 & $0,00 \%$ & 3,00 & $51,92 \%$ \\
\hline $\begin{array}{l}\text { empresas do Novo } \\
\text { Mercado (142 }\end{array}$ & $\begin{array}{c}\text { Desv. } \\
\text { Pad. }\end{array}$ & 2,07 & 0,69 & $11,51 \%$ & 2,11 & $22,71 \%$ \\
\hline empresas) & Mínimo & 3,00 & 0,00 & $0,00 \%$ & 0,00 & $0,00 \%$ \\
\hline & Máximo & 15,00 & 3,00 & $40,00 \%$ & 10,00 & $85,71 \%$ \\
\hline
\end{tabular}


Tabela 3: Estatística Descritiva

\begin{tabular}{|c|c|c|c|c|c|}
\hline Dados & & $\begin{array}{l}\text { Quantidade de } \\
\text { conselheiros } \\
\text { independentes }\end{array}$ & $\begin{array}{c}\% \text { de } \\
\text { conselheiros } \\
\text { independentes }\end{array}$ & $\begin{array}{l}\text { Conselheiros } \\
\text { eleitos pelo } \\
\text { controlador }\end{array}$ & $\begin{array}{c}\% \text { de } \\
\text { conselheiros } \\
\text { eleitos pelo } \\
\text { controlador }\end{array}$ \\
\hline & Média & 2,52 & $36,94 \%$ & 5,58 & $81,70 \%$ \\
\hline Categoria 1 (50 & Mediana & 2,00 & $33,33 \%$ & 6,00 & $87,50 \%$ \\
\hline $\begin{array}{l}\text { empresas): } \\
\text { controlador }\end{array}$ & $\begin{array}{l}\text { Desv. } \\
\text { Pad }\end{array}$ & 1,05 & $12,29 \%$ & 2,04 & $23,48 \%$ \\
\hline individual com mais & Mínimo & 1,00 & $14,29 \%$ & 0,00 & $0,00 \%$ \\
\hline & Máximo & 6,00 & $60,00 \%$ & 10,00 & $100,00 \%$ \\
\hline Categoria 1.1 (5 & Média & 2,00 & $34,38 \%$ & 4,20 & $79,14 \%$ \\
\hline empresas): & Mediana & 2,00 & $33,33 \%$ & 4,00 & $80,00 \%$ \\
\hline $\begin{array}{c}\text { controlador } \\
\text { individual com mais }\end{array}$ & $\begin{array}{l}\text { Desv. } \\
\text { Pad }\end{array}$ & 1,22 & $11,37 \%$ & 1,10 & $18,23 \%$ \\
\hline de $50 \%$ dos votos & Mínimo & 1,00 & $20,00 \%$ & 3,00 & $50,00 \%$ \\
\hline $\begin{array}{l}\text { via estrutura } \\
\text { indireta }\end{array}$ & Máximo & 4,00 & $50,00 \%$ & 6,00 & $100,00 \%$ \\
\hline & Média & 2,75 & $37,37 \%$ & 6,57 & $86,74 \%$ \\
\hline $\begin{array}{c}\text { Categoria } 2(28 \\
\text { empresas)・ }\end{array}$ & Mediana & 3,00 & $34,85 \%$ & 7,00 & $100,00 \%$ \\
\hline $\begin{array}{l}\text { empresas): controle } \\
\text { via acordo de }\end{array}$ & $\begin{array}{l}\text { Desv. } \\
\text { Pad. }\end{array}$ & 1,00 & $13,65 \%$ & 2,13 & $18,68 \%$ \\
\hline acionistas com mais & Mínimo & 1,00 & $16,67 \%$ & 2,00 & $33,33 \%$ \\
\hline & Máximo & 5,00 & $66,67 \%$ & 10,00 & $100,00 \%$ \\
\hline Categoria 3.1 (8 & Média & 2,50 & $37,37 \%$ & 3,25 & $50,28 \%$ \\
\hline empresas): & Mediana & 2,50 & $38,10 \%$ & 3,00 & $61,11 \%$ \\
\hline $\begin{array}{c}\text { controlador } \\
\text { individual com }\end{array}$ & $\begin{array}{l}\text { Desv. } \\
\text { Pad. }\end{array}$ & 1,20 & $11,25 \%$ & 3,24 & $44,25 \%$ \\
\hline menos de $50 \%$ dos & Mínimo & 1,00 & $20,00 \%$ & 0,00 & $0,00 \%$ \\
\hline votos & Máximo & 4,00 & $50,00 \%$ & 8,00 & $100,00 \%$ \\
\hline Categoria 3.2 (14 & Média & 2,64 & $34,79 \%$ & 6,71 & $80,03 \%$ \\
\hline empresas): controle & Mediana & 2,50 & $33,33 \%$ & 5,50 & $85,00 \%$ \\
\hline $\begin{array}{l}\text { via acordo de } \\
\text { acionistas com }\end{array}$ & $\begin{array}{l}\text { Desv. } \\
\text { Pad. }\end{array}$ & 1,01 & $12,14 \%$ & 3,85 & $22,45 \%$ \\
\hline menos de $50 \%$ dos & Mínimo & 1,00 & $16,67 \%$ & 2,00 & $33,33 \%$ \\
\hline & Máximo & 5,00 & $66,67 \%$ & 15,00 & $100,00 \%$ \\
\hline & Média & 4,08 & $58,84 \%$ & 0,35 & $5,15 \%$ \\
\hline Categoria 3.3 (37 & Mediana & 3,00 & $60,00 \%$ & 0,00 & $0,00 \%$ \\
\hline $\begin{array}{l}\text { empresas): empresas } \\
\text { sem controle }\end{array}$ & $\begin{array}{l}\text { Desv. } \\
\text { Pad. }\end{array}$ & 2,23 & $26,81 \%$ & 1,16 & $17,88 \%$ \\
\hline definido & Mínimo & 1,00 & $14,29 \%$ & 0,00 & $0,00 \%$ \\
\hline & Máximo & 8,00 & $100,00 \%$ & 5,00 & $83,33 \%$ \\
\hline & Média & 2,96 & $42,45 \%$ & 4,35 & $60,73 \%$ \\
\hline População de & Mediana & 3,00 & $38,75 \%$ & 5,00 & $76,39 \%$ \\
\hline $\begin{array}{l}\text { empresas do Novo } \\
\text { Mercado (142 }\end{array}$ & $\begin{array}{c}\text { Desv. } \\
\text { Pad. }\end{array}$ & 1,59 & $19,78 \%$ & 3,30 & $40,61 \%$ \\
\hline empresas) & Mínimo & 1,00 & $14,29 \%$ & 0,00 & $0,00 \%$ \\
\hline & Máximo & 8,00 & $100,00 \%$ & 15,00 & $100,00 \%$ \\
\hline
\end{tabular}


Tabela 3: Estatística Descritiva

\begin{tabular}{|c|c|c|c|c|c|}
\hline \multicolumn{2}{|l|}{ Dados } & $\begin{array}{c}\text { Conselheiros } \\
\text { independentes } \\
\text { eleitos pelo } \\
\text { controlador }\end{array}$ & $\begin{array}{c}\text { \% conselheiros } \\
\text { independentes } \\
\text { eleitos pelo } \\
\text { controlador }\end{array}$ & $\begin{array}{l}\text { \% de ações } \\
\text { do maior } \\
\text { acionista }\end{array}$ & $\begin{array}{c}\text { \% de ações } \\
\text { dos membros } \\
\text { de AC } \\
\text { controladores }\end{array}$ \\
\hline \multirow{5}{*}{$\begin{array}{c}\text { Categoria } 1 \text { ( } 50 \\
\text { empresas): } \\
\text { controlador } \\
\text { individual com mais } \\
\text { de } 50 \% \text { dos votos }\end{array}$} & Média & 1,56 & $60,13 \%$ & $61,89 \%$ & - \\
\hline & Mediana & 2,00 & $66,67 \%$ & $60,94 \%$ & - \\
\hline & Desv. & 1,34 & $42,25 \%$ & $10,75 \%$ & - \\
\hline & $\begin{array}{c}\text { Pad. } \\
\text { Mínimo }\end{array}$ & 0,00 & $0,00 \%$ & $50,00 \%$ & - \\
\hline & Máximo & 5,00 & $100,00 \%$ & $94,49 \%$ & - \\
\hline \multirow{5}{*}{$\begin{array}{c}\text { Categoria } 1.1 \text { ( } 5 \\
\text { empresas): } \\
\text { controlador } \\
\text { individual com mais } \\
\text { de } 50 \% \text { dos votos via } \\
\text { estrutura indireta }\end{array}$} & Média & 0,80 & $50,00 \%$ & $54,42 \%$ & - \\
\hline & Mediana & 1,00 & $50,00 \%$ & $52,39 \%$ & - \\
\hline & $\begin{array}{c}\text { Desv. } \\
\text { Pad. }\end{array}$ & 0,84 & $50,00 \%$ & $4,33 \%$ & - \\
\hline & Mínimo & 0,00 & $0,00 \%$ & $51,21 \%$ & - \\
\hline & Máximo & 2,00 & $100,00 \%$ & $61,93 \%$ & - \\
\hline \multirow{5}{*}{$\begin{array}{c}\text { Categoria } 2 \text { ( } 28 \\
\text { empresas): controle } \\
\text { via acordo de } \\
\text { acionistas com mais } \\
\text { de } 50 \% \text { dos votos }\end{array}$} & Média & 1,82 & $68,81 \%$ & $27,25 \%$ & $59,12 \%$ \\
\hline & Mediana & 2,00 & $100,00 \%$ & $28,42 \%$ & $57,90 \%$ \\
\hline & $\begin{array}{c}\text { Desv. } \\
\text { Pad. }\end{array}$ & 1,28 & $40,47 \%$ & $9,87 \%$ & $7,25 \%$ \\
\hline & Mínimo & 0,00 & $0,00 \%$ & $6,54 \%$ & $50,16 \%$ \\
\hline & Máximo & 4,00 & $100,00 \%$ & $46,59 \%$ & $73,75 \%$ \\
\hline \multirow{5}{*}{$\begin{array}{c}\text { Categoria } 3.1 \text { (8 } \\
\text { empresas): } \\
\text { controlador } \\
\text { individual com } \\
\text { menos de } 50 \% \text { dos } \\
\text { votos }\end{array}$} & Média & 0,63 & $25,00 \%$ & $25,52 \%$ & - \\
\hline & Mediana & 0,00 & $0,00 \%$ & $24,53 \%$ & - \\
\hline & $\begin{array}{l}\text { Desv. } \\
\text { Pad. }\end{array}$ & 1,19 & $46,29 \%$ & $9,87 \%$ & - \\
\hline & Mínimo & 0,00 & $0,00 \%$ & $6,50 \%$ & - \\
\hline & Máximo & 3,00 & $100,00 \%$ & $40,69 \%$ & - \\
\hline \multirow{5}{*}{$\begin{array}{c}\text { Categoria } 3.2(14 \\
\text { empresas): controle } \\
\text { via acordo de } \\
\text { acionistas com menos } \\
\text { de } 50 \% \text { dos votos }\end{array}$} & Média & 1,64 & $59,52 \%$ & $23,42 \%$ & $37,96 \%$ \\
\hline & Mediana & 1,50 & $75,00 \%$ & $23,21 \%$ & $37,77 \%$ \\
\hline & $\begin{array}{c}\text { Desv. } \\
\text { Pad. }\end{array}$ & 1,50 & $45,16 \%$ & $10,77 \%$ & $9,76 \%$ \\
\hline & Mínimo & 0,00 & $0,00 \%$ & $7,75 \%$ & $17,65 \%$ \\
\hline & Máximo & 5,00 & $100,00 \%$ & $38,25 \%$ & $49,62 \%$ \\
\hline \multirow{5}{*}{$\begin{array}{c}\text { Categoria } 3.3 \text { (37 } \\
\text { empresas): empresas } \\
\text { sem controle definido }\end{array}$} & Média & 0,11 & $4,05 \%$ & $17,27 \%$ & - \\
\hline & Mediana & 0,00 & $0,00 \%$ & $14,80 \%$ & - \\
\hline & $\begin{array}{c}\text { Desv. } \\
\text { Pad. }\end{array}$ & 0,52 & $18,17 \%$ & $9,13 \%$ & - \\
\hline & Mínimo & 0,00 & $0,00 \%$ & $0,00 \%$ & - \\
\hline & Máximo & 3,00 & $100,00 \%$ & $45,21 \%$ & - \\
\hline \multirow{5}{*}{$\begin{array}{c}\text { População de } \\
\text { empresas do Novo } \\
\text { Mercado (142 } \\
\text { empresas) }\end{array}$} & Média & 1,16 & $44,84 \%$ & $36,56 \%$ & - \\
\hline & Mediana & 1,00 & $50,00 \%$ & $30,80 \%$ & - \\
\hline & $\begin{array}{l}\text { Desv. } \\
\text { Pad. }\end{array}$ & 1,33 & $45,41 \%$ & $21,57 \%$ & - \\
\hline & Mínimo & 0,00 & $0,00 \%$ & $0,00 \%$ & - \\
\hline & Máximo & 5,00 & $100,00 \%$ & $94,49 \%$ & - \\
\hline
\end{tabular}

Fonte: Elaborada pelos autores. 
O Regulamento do Novo Mercado exige no mínimo $20 \%$ de conselheiros independentes, ou 2, o que for maior. A população de empresas estudadas apresenta uma média de 2,96 e mediana de 3,00 conselheiros independentes, além de um percentual médio de 42,45\% e mediana de $38,75 \%$, esse representando mais do que o dobro do mínimo exigido pelo regulamento. Conforme esperado, as 37 empresas sem controle definido (categoria 3.3) apresentam um percentual médio de conselheiros independentes consideravelmente superior às demais companhias, haja vista que "o papel dos conselheiros independentes é especialmente importante em companhias com capital disperso, sem controle definido, em que o papel predominante da diretoria deve ser contrabalançado" (IBGC, 2015, p. 45).

Tabela 4: Participação de conselheiros independentes nos CAs

\begin{tabular}{|c|c|c|c|}
\hline $\begin{array}{c}\text { \% de independentes no } \\
\text { conselho }\end{array}$ & Número de empresas & $\begin{array}{c}\text { \% do número de } \\
\text { empresas na população }\end{array}$ & $\begin{array}{c}\text { \% acumulado da } \\
\text { população }\end{array}$ \\
\hline Menor que 20\% & 6 & $4,23 \%$ & $4,23 \%$ \\
Entre 20\% e 39,9\% & 65 & $45,77 \%$ & $82,39 \%$ \\
Entre 40\% e 59,9\% & 46 & $32,39 \%$ & $93,66 \%$ \\
Entre 60\% e 80\% & 16 & $11,27 \%$ & $100,00 \%$ \\
\hline
\end{tabular}

Fonte: Elaborada pelos autores.

O regulamento do Novo Mercado, em vigor a partir de 02/01/2018, estabelece o prazo até a assembleia geral ordinária que deliberar as demonstrações financeiras referentes ao exercício social de 2020 para que as companhias se adequem a nova regra de no mínimo 2 conselheiros independentes. De acordo com as informações coletadas da base de dados ComDinheiro® em 04 de novembro 2018, as empresas BB SEGURIDADE PARTICIPAÇÕES S.A., BK BRASIL OPERAÇÃO E ASSESSORIA A RESTAURANTES S.A., CCX CARVÃO DA COLÔMBIA S.A., CYRELA COMMERCIAL PROPERTIES S.A. EMP PART, GRENDENE S.A., LPS BRASIL CONSULTORIA DE IMOVEIS S.A., METALFRIO SOLUTIONS S.A., MMX MINERAÇÃO E METÁLICOS S.A., MOVIDA PARTICIPAÇÕES S.A., OSX BRASIL S.A., PARANAPANEMA S.A., PORTO SEGURO S.A., RENAR MAÇAS S.A., ROSSI RESIDENCIAL S.A., TRISUL S.A., UNICASA INDÚSTRIA DE MÓVEIS S.A. e VIVER INCORPORADORA E CONSTRUTORA S.A. apresentaram apenas 1 conselheiro independente no conselho de administração até a referida data.

Já as empresas BB SEGURIDADE PARTICIPAÇÕES S.A., BK BRASIL OPERAÇÃO E ASSESSORIA A RESTAURANTES S.A., GRENDENE S.A., PARANAPANEMA S.A., PORTO SEGURO S.A. e VALE S.A. possuem menos de $20 \%$ de conselheiros independentes compondo o quadro efetivo do conselho de administração, logo estão descumprindo o regulamento do Novo Mercado haja vista que o prazo para adequação se refere apenas ao mínimo de 2 conselheiros independentes, quando esse número representar mais de $20 \%$ do conselho.

Ademais cabe destacar o elevado percentual de conselheiros independentes eleitos pelo controlador, particularmente nas categorias 2 e 3.2, cujo controle está estabelecido mediante 
acordo de acionistas. Os valores encontrados, de 68,81\% e 59,52\% respectivamente, demonstram a capacidade que esses mecanismos possuem de modificar efetivamente o grau de concentração de propriedade dentro das empresas. Devido aos valores percentuais elevados para essa variável, é razoável o questionamento quanto a possível perda de independência do conselho, visto que esses conselheiros declarados independentes foram eleitos pelo acionista ou bloco de acionistas controlador, tratando-se de figura dominante dentro da firma com a capacidade de expropriar os acionistas minoritários.

Cabe ainda chamar a atenção para as variáveis de conselheiros eleitos pelo controlador e os conselheiros independentes eleitos pelo controlador, ambos para o grupo de companhias sem controle definido (categoria 3.3). Como nessas empresas não há controlador, esperava-se encontrar essas variáveis zeradas para esta categoria de firmas. Entretanto, as empresas CVC BRASIL OPERADORA E AGÊNCIA DE VIAGENS S.A., EQUATORIAL ENERGIA S.A., INTERNATIONAL MEAL COMPANY ALIMENTAÇÃO S.A. e IOCHPE MAXION S.A. estranhamente indicaram a presença de conselheiros eleitos pelo controlador apesar de terem uma estrutura de propriedade dispersa, sem existir de fato um acionista controlador mesmo se observada à estrutura indireta. $\mathrm{O}$ presente estudo não conseguiu identificar uma explicação plausível para esse fenômeno exceto eventuais erros por parte das empresas ao informar os dados para a CVM.

Analisando-se as empresas do Novo Mercado quanto ao grau de concentração de propriedade, detectou-se que o maior acionista individual controla em média 36,56\% do capital votante das firmas. Todavia ao considerar a soma das participações individuais dos membros de acordo de acionistas que estabeleça controle como representante do percentual do maior proprietário, então a média populacional da participação de propriedade do maior acionista sobe para 45,05\%. Esses valores são semelhantes aos observados por Gorga (2009) em seu estudo, no qual ela apresenta a média do capital votante do maior acionista para as empresas do Novo Mercado de 36,39\%, subindo para 45,25\% ao considerar os acordos de acionistas.

\subsection{Testes estatísticos}

A tabela 5 apresenta os resultados do teste de análise de variância (ANOVA) entre todas as categorias de controle identificadas na tabela 2, visando verificar possíveis diferenças entre os grupos para as variáveis quantitativas da tabela 1. No entanto, como a premissa de homogeneidade entre as variâncias dos grupos não foi atendida, conforme resultados dos testes de Levene, optou-se pela realização do teste não paramétrico de Kruskal-Wallis.

Os resultados do teste de Kruskal-Wallis apresentados na tabela 5 demonstram que as medianas populacionais das categorias de controle não são estatisticamente todas iguais para as variáveis testadas, exceto quanto ao tamanho efetivo do $\mathrm{CA}$, a quantidade de conselheiros internos e ao percentual de conselheiros internos.

Tabela 5: testes ANOVA e Kruskal-Wallis

\begin{tabular}{|c|c|c|c|}
\hline \multirow{2}{*}{ Variável } & \multicolumn{2}{|c|}{ P-valor } \\
\cline { 2 - 4 } & ANOVA & $\begin{array}{c}\text { Homogeneidade } \\
\text { (Levene) }\end{array}$ & Kruskal-Wallis \\
\hline Tamanho efetivo do CA & 0,102 & 0,019 & 0,261 \\
\hline Quantidade de conselheiros internos & 0,475 & $\mathbf{0 , 7 8 1}$ & 0,429 \\
\hline$\%$ de conselheiros internos & 0,359 & $\mathbf{0 , 9 2 2}$ & 0,326 \\
\hline Quantidade de conselheiros externos & $4,29 \mathrm{E}-04 * * *$ & 0,034 & $0,001^{* * *}$ \\
\hline$\%$ de conselheiros externos & $2,15 \mathrm{E}-04 * * *$ & 0,005 & $0,003 * * *$ \\
\hline Quantidade de conselheiros independentes & $3,85 \mathrm{E}-05^{* * *}$ & 0,043 & $0,009^{* * *}$ \\
\hline$\%$ de conselheiros independentes & $2,76 \mathrm{E}-07^{* * *}$ & 0,000 & $0,001^{* * *}$ \\
\hline
\end{tabular}


Tabela 5: testes ANOVA e Kruskal-Wallis

\begin{tabular}{|c|c|c|c|}
\hline \multirow[b]{2}{*}{ Variável } & \multicolumn{3}{|c|}{ P-valor } \\
\hline & ANOVA & $\begin{array}{l}\text { Homogeneidade } \\
\text { (Levene) }\end{array}$ & Kruskal-Wallis \\
\hline Conselheiros eleitos pelo controlador & $<2 \mathrm{E}-16 * * *$ & 0,000 & $2,34 \mathrm{E}-12 * * *$ \\
\hline$\%$ de conselheiros eleitos pelo controlador & $<2 \mathrm{E}-16 * * *$ & 0,000 & $3,59 \mathrm{E}-12 * * *$ \\
\hline $\begin{array}{l}\text { Conselheiros independentes eleitos pelo } \\
\text { controlador }\end{array}$ & $3,84 \mathrm{E}-08 * * *$ & 0,001 & $6,15 \mathrm{E}-06 * * *$ \\
\hline $\begin{array}{l}\% \text { de conselheiros independentes eleitos pelo } \\
\text { controlador }\end{array}$ & $1,42 \mathrm{E}-10 * * *$ & 0,004 & $4,13 \mathrm{E}-06 * * *$ \\
\hline$\%$ de ações do maior acionista & $<2 \mathrm{E}-16 * * *$ & 0,296 & $<2 \mathrm{E}-16^{* * * *}$ \\
\hline $\begin{array}{c}\% \text { de ações dos membros de acordo de } \\
\text { acionistas controladores }\end{array}$ & $9,89 \mathrm{E}-10 * * *$ & $\mathbf{0 , 3 1 9 2}$ & $<2 \mathrm{E}-16^{* * * *}$ \\
\hline
\end{tabular}

Fonte: Elaborada pelos autores.

Entretanto, apesar dos resultados do teste ANOVA não serem robustos devido ao não atendimento da premissa de homogeneidade de variâncias, chama a atenção o fato de terem sido encontradas diferenças entre as médias e as medianas das categorias, respectivamente nos testes ANOVA e de Kruskal-Wallis, para as mesmas variáveis em ambos os casos.

Por sua vez, a tabela 6 traz os resultados de dois testes t de diferenças entre médias, t.1 e t.2, com ambos tendo atendido a premissa de normalidade. O teste t.1 agrupou as categorias de controle em duas classes, uma contendo todas as empresas que apresentavam algum tipo de controle com mais de $50 \%$ dos votos e a outra englobando o restante das companhias. Esse agrupamento se justifica porque o presente estudo inicialmente considerou o mesmo parâmetro utilizado tradicionalmente nas pesquisas nacionais (LEAL; SILVA; VALADARES, 2002; GORGA, 2009; BORTOLON, 2013; ALDRIGHI; POSTALI; DIAZ, 2018), no qual são considerados como controladores apenas acionistas individuais ou blocos de membros de acordo de acionistas que detenham mais de $50 \%$ do capital votante das firmas.

$\mathrm{O}$ teste $\mathrm{t} .2$ teve como foco a informação que as próprias empresas forneceram a CVM. Assim sendo, na classe 1 estão presentes todas as empresas que informaram existir algum tipo de controle, seja ele individual ou via acordo de acionistas, independente do percentual do proprietário ou bloco de sócios informado como controlador, enquanto que a classe 2 contém todas as sociedades que foram informadas como não tendo um controlador definido.

Conforme tabela 6 , os resultados dos testes t.1 e t.2 demonstram que, para ambos os testes, a diferença entre as médias das classes estatisticamente diferente de zero para todas as variáveis testadas, exceto quanto ao tamanho efetivo do CA, a quantidade de conselheiros internos e ao percentual de conselheiros internos. Este resultado é semelhante ao encontrado anteriormente no teste de Kruskal-Wallis.

Tabela 6: testes $\mathbf{t}$ de diferença entre médias

\begin{tabular}{|c|c|c|c|c|c|c|}
\hline \multirow{2}{*}{ Variável } & \multicolumn{3}{|c|}{ Teste t.1 } & \multicolumn{2}{c|}{ Teste t.2 } \\
\cline { 2 - 7 } & $\begin{array}{c}\text { Classe 1 } \\
\mathbf{8 3} \\
\text { empresas } \\
\text { Média 1 }\end{array}$ & $\begin{array}{c}\text { Classe 2 } \\
\mathbf{5 9} \\
\text { empresas } \\
\text { Média 2 }\end{array}$ & Estatística t & $\begin{array}{c}\text { Classe 1 } \\
\mathbf{1 0 5} \text { empresas } \\
\text { Média 1 }\end{array}$ & $\begin{array}{c}\text { Classe 2 } \\
\text { 37 empresas } \\
\text { Média 2 }\end{array}$ & $\begin{array}{c}\text { Estatística } \\
\text { t }\end{array}$ \\
\hline $\begin{array}{c}\text { Tamanho efetivo do } \\
\text { CA }\end{array}$ & 7,02 & 7,14 & $-0,30$ & 7,12 & 6,92 & 0,53 \\
\hline $\begin{array}{c}\text { Quantidade de } \\
\text { conselheiros internos }\end{array}$ & 0,60 & 0,56 & 0,37 & 0,63 & 0,46 & 1,34 \\
\hline $\begin{array}{c}\text { \% de conselheiros } \\
\text { internos }\end{array}$ & $9,55 \%$ & $9,29 \%$ & 0,13 & $9,94 \%$ & $8,04 \%$ & 0,83 \\
\hline $\begin{array}{c}\text { Quantidade de } \\
\text { conselheiros externos }\end{array}$ & 3,86 & 3,05 & $2,15^{* *}$ & 3,92 & 2,38 & $3,85^{* * *}$ \\
\hline
\end{tabular}


Tabela 6: testes $\mathbf{t}$ de diferença entre médias

\begin{tabular}{|c|c|c|c|c|c|c|}
\hline \multirow[b]{2}{*}{ Variável } & \multicolumn{3}{|c|}{ Teste t.1 } & \multicolumn{3}{|c|}{ Teste t.2 } \\
\hline & $\begin{array}{l}\text { Classe } 1 \\
83 \\
\text { empresas } \\
\text { Média } 1\end{array}$ & $\begin{array}{c}\text { Classe } 2 \\
59 \\
\text { empresas } \\
\text { Média } 2\end{array}$ & Estatística $\mathbf{t}$ & $\begin{array}{c}\text { Classe } 1 \\
105 \text { empresas } \\
\text { Média } 1 \\
\end{array}$ & $\begin{array}{c}\text { Classe } 2 \\
37 \text { empresas } \\
\text { Média } 2 \\
\end{array}$ & $\begin{array}{c}\text { Estatística } \\
\mathbf{t}\end{array}$ \\
\hline $\begin{array}{c}\% \text { de conselheiros } \\
\text { externos }\end{array}$ & $53,51 \%$ & $40,49 \%$ & $3,30 * * *$ & $53,38 \%$ & $33,12 \%$ & $4,12 * * *$ \\
\hline $\begin{array}{c}\text { Quantidade de } \\
\text { conselheiros } \\
\text { independentes } \\
\end{array}$ & 2,57 & 3,53 & $-3,36 * * *$ & 2,57 & 4,08 & $-3,97 * * *$ \\
\hline $\begin{array}{c}\% \text { de conselheiros } \\
\text { independentes }\end{array}$ & $36,93 \%$ & $50,22 \%$ & $-3,76 * * *$ & $36,68 \%$ & $58,84 \%$ & $-4,85 * * *$ \\
\hline $\begin{array}{l}\text { Conselheiros eleitos } \\
\text { pelo controlador }\end{array}$ & 5,83 & 2,25 & $6,91 * * *$ & 5,75 & 0,35 & $17,09 * * *$ \\
\hline $\begin{array}{c}\% \text { de conselheiros } \\
\text { eleitos pelo } \\
\text { controlador }\end{array}$ & $83,25 \%$ & $29,04 \%$ & $9,47 * * *$ & $80,31 \%$ & $5,15 \%$ & $19,58 * * *$ \\
\hline $\begin{array}{c}\text { Conselheiros } \\
\text { independentes eleitos } \\
\text { pelo controlador }\end{array}$ & 1,60 & 0,54 & $5,19 * * *$ & 1,53 & 0,11 & $9,16 * * *$ \\
\hline $\begin{array}{c}\% \text { de conselheiros } \\
\text { independentes eleitos } \\
\text { pelo controlador }\end{array}$ & $62,45 \%$ & $20,06 \%$ & $6,25^{* * *}$ & $59,21 \%$ & $4,05 \%$ & $10,65 * * *$ \\
\hline $\begin{array}{c}\text { \% de ações do maior } \\
\text { acionista }\end{array}$ & $49,76 \%$ & $19,85 \%$ & $12,08 * * *$ & $44,40 \%$ & $17,27 \%$ & $10,85^{* * * *}$ \\
\hline
\end{tabular}

Teste 1 - Classe 1: Categorias 1, 1.1 e 2; Classe 2: Categorias 3.1, 3.2 e 3.3.

Teste 2 - Classe 1: Categorias 1, 1.1, 2, 3.1 e 3.2; Classe 2: Categoria 3.3.

Categoria 1 - Controlador Individual com mais de 50\% dos votos; Categoria 1.1 - Controlador individual com mais de 50\% dos votos via estrutura indireta; Categoria 2 - Controle via acordo de acionistas somando mais de 50\% dos votos; Categoria 3.1 - Controle individual com menos de 50\% dos votos; Categoria 3.2 -

Controle via acordo de acionistas somando menos de 50\% dos votos; Categoria 3.3 - Sem controle definido.

Fonte: Elaborada pelos autores.

Analisando-se o valor da estatística t dos testes t.1 e t.2, percebe-se que para todas as variáveis que apresentaram as médias das classes estatisticamente diferentes de zero, com exceção do percentual de ações do maior acionista, o resultado do teste t. 2 foi mais significativo do que t.1. Como o teste t.1 compara empresas com controlador possuindo mais de $50 \%$ dos votos contra o restante das firmas, e o teste t. 2 compara todas as empresas que informam ter algum tipo de controlador (independente do percentual de votos) contra as companhias de capital disperso, o fato de t.2 apresentar resultados mais significativos levanta um questionamento quanto a real efetividade do corte acima de $50 \%$ do capital votante para um acionista ser considerado como controlador.

Diante disso, foi então realizado um novo teste $t$ de diferenças entre médias, chamado t.3. Neste a classe 1 está composta pelas empresas que apresentam algum tipo de controle com mais de $50 \%$ dos votos e a classe 2 agrupou as empresas que informaram a presença de acionista controlador detendo menos de $50 \%$ do capital votante. Todavia o teste t.3 não atendeu a premissa de normalidade, conforme resultados apresentados na tabela 7. Com isso, procedeuse a realização do teste não paramétrico de Wilcoxon-Mann-Whitney para as mesmas classes de t.3, com o objetivo de verificar se existe diferença estatisticamente significativa entre as medianas das companhias do Novo Mercado para as variáveis analisadas, considerando como requisito para assumir o controle a posse de $50 \%$ do capital votante de um lado e do outro não. 
Tabela 7: testes t de diferença entre médias e teste de Wilcoxon

\begin{tabular}{|c|c|c|c|c|c|c|}
\hline \multirow{3}{*}{ Variável } & \multicolumn{5}{|c|}{ Teste t.3 } & \multirow{3}{*}{$\begin{array}{c}\text { Teste de } \\
\text { Wilcoxon-Mann- } \\
\text { Whitney } \\
\text { (p-valor) }\end{array}$} \\
\hline & \multirow{2}{*}{$\begin{array}{c}\text { Classe } 1 \\
83 \text { empresas } \\
\text { Média } 1\end{array}$} & \multirow{2}{*}{$\begin{array}{l}\text { Classe } 2 \\
22 \\
\text { empresas } \\
\text { Média } 2\end{array}$} & \multirow[b]{2}{*}{ Estatística $\mathbf{t}$} & \multicolumn{2}{|c|}{$\begin{array}{c}\text { Normalidade } \\
\text { (Shapiro-Wilk) }\end{array}$} & \\
\hline & & & & $\begin{array}{l}\text { Classe } 1 \\
\text { (p-valor) }\end{array}$ & $\begin{array}{l}\text { Classe } 2 \\
\text { (p-valor) }\end{array}$ & \\
\hline Tamanho efetivo do CA & 7,024 & 7,500 & $-0,730$ & $6,48 \mathrm{E}-03$ & 0,174 & 0,777 \\
\hline $\begin{array}{c}\text { Quantidade de } \\
\text { conselheiros internos }\end{array}$ & 0,602 & 0,727 & $-0,690$ & $1,41 \mathrm{E}-07$ & $1,25 \mathrm{E}-04$ & 0,513 \\
\hline $\begin{array}{c}\% \text { de conselheiros } \\
\text { internos }\end{array}$ & $9,55 \%$ & $11,39 \%$ & $-0,650$ & $3,12 \mathrm{E}-06$ & 0,005 & 0,524 \\
\hline $\begin{array}{c}\text { Quantidade de } \\
\text { conselheiros externos }\end{array}$ & 3,855 & 4,182 & $-0,560$ & 0,027 & 0,007 & 0,914 \\
\hline $\begin{array}{c}\% \text { de conselheiros } \\
\text { externos }\end{array}$ & $53,51 \%$ & $52,89 \%$ & 0,150 & 0,028 & 0,476 & 0,662 \\
\hline $\begin{array}{c}\text { Quantidade de } \\
\text { conselheiros } \\
\text { independentes } \\
\end{array}$ & 2,566 & 2,591 & $-0,090$ & 0,002 & $\mathbf{0 , 0 5 5}$ & 0,822 \\
\hline $\begin{array}{c}\% \text { de conselheiros } \\
\text { independentes }\end{array}$ & $36,93 \%$ & $35,73 \%$ & 0,430 & 0,009 & 0,312 & 0,325 \\
\hline $\begin{array}{l}\text { Conselheiros eleitos } \\
\text { pelo controlador }\end{array}$ & 5,831 & 5,455 & 0,430 & 0,031 & 0,248 & 0,849 \\
\hline $\begin{array}{l}\% \text { de conselheiros } \\
\text { eleitos pelo controlador }\end{array}$ & $83,25 \%$ & $69,21 \%$ & 1,820 & 5,99E-07 & 0,001 & 0,102 \\
\hline $\begin{array}{c}\text { Conselheiros } \\
\text { independentes eleitos } \\
\text { pelo controlador }\end{array}$ & 1,602 & 1,273 & 0,970 & 0,011 & 0,001 & 0,236 \\
\hline $\begin{array}{c}\% \text { de conselheiros } \\
\text { independentes eleitos } \\
\text { pelo controlador }\end{array}$ & $62,45 \%$ & $46,97 \%$ & 1,390 & 2,29E-07 & 0,033 & 0,181 \\
\hline $\begin{array}{c}\text { \% de ações do maior } \\
\text { acionista }\end{array}$ & $49,76 \%$ & $24,18 \%$ & $8,429 * * *$ & 0,027 & 0,499 & $1,90 \mathrm{E}-07 * * *$ \\
\hline
\end{tabular}

Teste 3 - Classe 1: Categorias 1, 1.1 e 2; Classe 2: Categorias 3.1 e 3.2.

Categoria 1 - Controlador Individual com mais de 50\% dos votos; Categoria 1.1 - Controlador individual com mais de 50\% dos votos via estrutura indireta; Categoria 2 - Controle via acordo de acionistas somando mais de $50 \%$ dos votos; Categoria 3.1 - Controle individual com menos de 50\% dos votos; Categoria 3.2 - Controle via acordo de acionistas somando menos de 50\% dos votos; Categoria 3.3 - Sem controle definido.

Fonte: Elaborada pelos autores.

Os resultados do teste de Wilcoxon-Mann-Whitney (tabela 7) revelam que pesquisas que estudam a estrutura dos conselhos de administração das empresas do Novo Mercado e consideram como acionistas controladores somente aqueles que somam mais de 50\% do capital votante podem estar cometendo um equívoco, haja vista que não foram encontradas diferenças estatisticamente significativas entre as medianas das classes para as variáveis testadas, exceto para o percentual de ações do maior acionista, porém isto era esperado devido à divisão proposta para as classes. 


\section{Considerações finais}

Este estudo foi realizado com o objetivo de analisar a relação entre a configuração dos conselhos de administração e a estrutura de propriedade e controle das empresas do Novo Mercado. Com base na literatura, a relação entre esses fatores indica a capacidade dos acionistas de exercer o controle da empresa, permitindo verificar se o corte de maioria absoluta dos votos é a única forma de garantir o controle das firmas.

A análise e interpretação dos dados referentes ao conselho de administração e a estrutura de propriedade, provenientes do ComDinheiro®, dos formulários de referência e dos acordos de acionistas vigentes das 142 empresas do Novo Mercado em 04 de novembro de 2018, permitiu compreender como estas estruturas estão configuradas e relacionadas entre si.

Os dados apontam a existência de altos percentuais de conselheiros, inclusive independentes, eleitos pelo acionista ou bloco de acionistas controlador. Isso gera incerteza sobre uma possível perda de independência dos conselheiros e do conselho como um todo, haja vista terem sido eleitos por uma figura preponderante dentro da empresa. Uma das formas de remediar este possível problema seria a criação de limitações na quantidade permitida de conselheiros independentes eleitos pelo bloco controlador, ou, de forma mais drástica, a modificação do conceito de independência aceito pelo regulamento do Novo Mercado para não incluir conselheiros eleitos por acionistas controladores.

Os resultados dos testes apontam ausência de diferenças estatisticamente significativas entre empresas com acionistas controladores absolutos (com mais de 50\% dos votos) e empresas com controladores autodeclarados, que não possuem maioria absoluta do capital votante. Isto implica que o corte de maioria absoluta dos votos, tradicionalmente utilizado em pesquisas nacionais devido à alta concentração de propriedade das empresas brasileiras, pode não ser a prática mais recomendável. De acordo com as evidências encontradas para o Novo Mercado, cujas empresas apresentam uma concentração acionária menor do que nos demais segmentos de listagem, acionistas com percentuais inferiores a $50 \%$ também podem de fato exercer o controle das firmas, assemelhando-se ao que ocorre em mercados com predominância da estrutura dispersa.

Todavia, apesar da diminuição inicial na concentração de propriedade das empresas do Novo Mercado após a sua criação, contatou-se que a situação se manteve sem alterações significativas na última década, mesmo com o aumento do número de empresas nele listadas.

Sugere-se para estudos futuros ampliar a investigação quanto a existência de diferenças entre as empresas com acionistas controladores com maioria absoluta do capital votante e com controladores autodeclarados, observando-se outras características além das do conselho de administração, ou ainda estendendo o estudo para empresas de outros segmentos de listagem da B3. Além disso, sugere-se investigar se há evidências de perda de independência por parte dos conselheiros eleitos pelo acionista ou bloco controlador.

\section{Referências}

ALDRIGHI, D. M.; MAZZER NETO, R. Estrutura de propriedade e de controle das empresas de capital aberto no Brasil. Revista de Economia Política, v. 25, n. 2, p. 115-137, abr. 2005.

ALDRIGHI, D. M.; MAZZER NETO, R. Evidências sobre as estruturas de propriedade de capital e de voto das empresas de capital aberto no Brasil. Revista Brasileira de Economia, v. 61, n. 2, p. 129-152, 2007.

ALDRIGHI, D. M.; POSTALI, F. A. S.; DIAZ, M. D. M. Corporate Governance and Pyramidal Ownership: The Role of Novo Mercado. Brazilian Review of Finance, v. 16, n. 1, p. 5, 2018. 
ALVES, P.; COUTO, E. B.; FRANCISCO, P. M. Board of directors' composition and capital structure. Research in International Business and Finance, v. 35, p. 1-32, set. 2015.

ANDERSON, R. C.; REEB, D. M. Board Composition: Balancing Family Influence in S\&P 500 Firms. Administrative Science Quarterly, v. 49, n. 2, p. 209-237, 2004.

ANDRADE, L. P. D. et al. GOVERNANÇA CORPORATIVA: UMA ANÁLISE DA RELAÇÃO DO CONSELHO DE ADMINISTRAÇÃO COM O VALOR DE MERCADO E DESEMPENHO DAS EMPRESAS BRASILEIRAS. REVISTA DE ADMINISTRAÇÃO MACKENZIE, v. 10, n. 4, p. 4-31, 2009.

BORTOLON, P. M. POR QUE AS EMPRESAS BRASILEIRAS ADOTAM ESTRUTURAS PIRAMIDAIS DE CONTROLE. Revista Base (Administração e Contabilidade) da UNISINOS, v. 10, n. 1, p. 2-18, 2013.

BRASIL, BOLSA, BALCÃO [B3]. REGULAMENTO DO NOVO MERCADO. 2017.

BRUGNI, T. V. et al. Corporate governance: A panoramic view of Brazilian boards of directors. International Journal of Disclosure and Governance, v. 10, n. 4, p. 406-421, 2013.

BRUGNI, T. V. et al. CONSELHOS DE ADMINISTRAÇÃO BRASILEIROS: UMA ANÁLISE À LUZ DOS FORMULÁRIOS DE REFERÊNCIA. Advances in Scientific and Applied Accounting, v. 11, n. 1, p. 146-165, 2018.

BYRD, J. W.; HICKMAN, K. A. Do outside directors monitor managers? Journal of Financial Economics, v. 32, n. 2, p. 195-221, 1992.

CAIXE, D. F.; KRAUTER, E. A influência da estrutura de propriedade e controle sobre o valor de mercado corporativo no Brasil. Revista Contabilidade \& Finanças, v. 24, n. 62, p. 142 $153,2013$.

CARVALHAL, A. L. Do shareholder agreements affect market valuation? Evidence from Brazilian listed firms. Journal of Corporate Finance, v. 18, p. 919/933, 2012.

CARVALHAL DA SILVA, A.; LEAL, R. P. C. Corporate Governance, Market Valuation and Dividend Policy in Brazil. Coppead Working Papers Series, v. 390, 2003.

CHAVEZ, G. A.; SILVA, A. C. Brazil's Experiment with Corporate Governance. Journal of Applied Corporate Finance, v. 21, n. 1, p. 34-44, 2009.

CLAESSENS, S.; DJANKOV, S.; LANG, L. H. P. The Separation of Ownership and Control in East Asian Corporations. Journal of Financial Economics, v. 58, n. 1, p. 81-112, 2000.

CLARKE, D. C. Three Concepts of the Independent Director. Delaware Journal of Corporate Law, v. 32, n. 1, p. 73-111, 2007.

CORBETTA, G.; SALVATO, C. A. The Board of Directors in Family Firms: One Size Fits All? Family Business Review, v. 17, n. 2, p. 119-134, 2004.

DAHYA, J.; DIMITROV, O.; MCCONNELL, J. J. Dominant shareholders, corporate boards, and corporate value: A cross-country analysis. Journal of Financial Economics, v. 87, n. 1, p. 73-100, 2008. 
DE ANDRADE, L. P.; BRESSAN, A. A.; IQUIAPAZA, R. A. Estrutura Piramidal de Controle, Emissão de Duas Classes de Ações e Desempenho Financeiro das Empresas Brasileiras. Revista Brasileira de Finanças, v. 12, n. 4, p. 555-595, 2014.

DE OLIVEIRA, G. C.; WOLF, P. J. W. A DINÂMICA DO MERCADO DE CRÉDITO NO BRASIL NO PERÍODO RECENTE (2007-2015). Texto para Discussão: IPEA, n. 2243, 2016.

DUTRA, M. G. L.; SAITO, R. Conselhos de administração: análise de sua composição em um conjunto de companhias abertas brasileiras. Revista de Administração Contemporânea, v. 6, n. 2, p. 9-27, ago. 2002.

FONTES FILHO, J. R.; PICOLIN, L. M. Governança corporativa em empresas estatais: avanços, propostas e limitações. Revista de Administração Pública, v. 42, n. 6, p. 1163-1188, 2008 .

GELMAN, M. O. O CONCEITO DE CONSELHEIRO INDEPENDENTE VIGENTE NA REGULAMENTAÇÃO DOS NÍVEIS DIFERENCIADOS DE GOVERNANÇA CORPORATIVA DA BM\&FBOVESPA. São Paulo: Fundação Getúlio Vargas, 2012.

GORDON, J. N. The Rise of Independent Directors in the United States, 1950-2005: Of Shareholder Value and Stock Market Prices. Stanford Law Review, v. 59, n. 6, p. 1465-1568, 2010.

GORGA, E. Changing the Paradigm of Stock Ownership: From Concentrated Towards Dispersed Ownership? Evidence from Brazil and Consequences for Emerging Countries. Northwestern Journal of International Law \& Business, v. 29, n. 2, p. 439-554, 2009.

INSTITUTO BRASILEIRO DE GOVERNANÇA CORPORATIVA [IBGC]. Código das melhores práticas de governança corporativa. $5^{\text {a }}$ edição. 2015.

JENSEN, C.; MECKLING, H. THEORY OF THE FIRM: MANAGERIAL BEHAVIOR, AGENCY COSTS AND OWNERSHIP STRUCTURE. Journal of Financial Economics, v. 3, n. 4, p. 305-360, 1976.

LA PORTA, R.; LOPEZ-DE-SILANES, F.; SHLEIFER, A. Corporate Ownership Around the World. The Journal of Finance, v. 54, n. 2, p. 471-517, abr. 1999.

LEAL, R. P. C.; CARVAlHAL, A. L.; IERVOLINO, A. P. One Decade of Evolution of Corporate Governance Practices in Brazil. Brazilian Review of Finance, v. 13, n. 1, p. 134$161,2015$.

LEAL, R. P. C.; SILVA, A. L. C. DA; VALADARES, S. M. Estrutura de controle das companhias brasileiras de capital aberto. Revista de Administração Contemporânea, v. 6, n. 1, p. $7-18,2002$.

NEVES, A. C. D. et al. DIAGNÓSTICO E ANÁLISE DAS COMPETÊNCIAS DOS CONSELHEIROS DE ADMINISTRAÇÃO. Revista de Administração de Empresas, v. 57 , n. 5, p. 453-469, set. 2017.

OKIMURA, R. T.; SILVEIRA, A. DI M. DA; ROCHA, K. C. Estrutura de Propriedade e Desempenho Corporativo no Brasil. RAC - Eletrônica, v. 1, n. 1, p. 119-135, 2007. 
PROCIANOY, J. L.; SCHNORRENBERGER, A. A Influência da Estrutura de Controle nas Decisões de Estrutura de Capital das Companhias Brasileiras. Revista Brasileira de Economia, v. 58, n. 1, p. 121-146, 2004.

SHLEIFER, A.; VISHNY, R. W. A Survey of Corporate Governance. The Journal of Finance, v. 52, n. 2, p. 737-783, 1997.

STERNBERG, L.; LEAL, R. P. C.; BORTOLON, P. M. Affinities and agreements among major Brazilian shareholders. International Journal of Disclosure and Governance, v. 8, n. 3, p. 213-228, 2011.

VALADARES, S. M.; LEAL, R. P. C. Ownership and Control Structure of Brazilian Companies. Abante, Escuela de Administracion. Pontificia Universidad Católica de Chile., v. 3, n. 1, p. 29-56, 2000.

VILLALONGA, B. et al. What Are Boards For? Evidence from Closely Held Firms in Colombia: What Are Boards For? Financial Management, v. 48, n. 2, p. 537-573, 2018. 